Article

\title{
Exploring the Contested Notion of Social Inclusion and Gender Inclusivity within eSport Spaces
}

\author{
Emily Jane Hayday * and Holly Collison \\ Institute for Sport Business, Loughborough University London, London, E20 3BS, UK; E-Mails: e.hayday@lboro.ac.uk (E.J.H.), \\ h.collison@lboro.ac.uk (H.C.) \\ * Corresponding author
}

Submitted: 31 December 2019 | Accepted: 12 May 2020 | Published: 17 August 2020

\begin{abstract}
With an emphasis on virtual engagement, creativity, and diverse competitive platforms, eSport is being explored as a new activity to achieve development outcomes within the Sport for Development (SfD) movement (Kidd, 2008). Research has shown the potential of eSport to provide opportunities for social interaction, bonding, and building social capital (Trepte, Reinecke, \& Juechems, 2012). This exploratory research, conducted in 2019, examines the current eSport landscape and utility of eSport as a space to enact social inclusion and more specifically, in-line with SfD agendas and goals, positive experiences for women and girls. Three interactive focus groups were conducted in the UK and USA ( $N=65$ ) involving key stakeholders, including game publishers, SfD organisations, eSport teams, tournament organisers, and gamers. Supplementary interviews $(\mathrm{N}=16$ ) were conducted to allow for richer accounts and perspectives to be examined. Findings exposed the contested notion of social inclusion within online gaming communities as evidenced by the dominant masculine dynamics of digital spaces. Consistently those engaged in eSport claimed social inclusion and inclusivity were the most significant features and offering to the SfD movement. Yet, simultaneously the same voices exposed toxicity in the form of gender inequality and discrimination as the challenge embedded within eSport among its rapidly growing participants and spectators. This article empirically examines gender dynamics within eSport spaces, using Bailey's social inclusion theory and Lefebvre's spatial theory, and critically presents new opportunities to the field of SfD.
\end{abstract}

\section{Keywords}

communities; eSport; gaming; gender; social inclusion; sport for development; toxicity

Issue

This article is part of the issue "Sport for Development: Opening Transdisciplinary and Intersectoral Perspectives" edited by Pascal Delheye (Ghent University, Belgium), Kirsten Verkooijen (Wageningen University \& Research, The Netherlands), Dan Parnell (University of Liverpool, UK), John Hayton (Northumbria University, UK) and Reinhard Haudenhuyse (Vrije Universiteit Brussel, Belgium).

(C) 2020 by the authors; licensee Cogitatio (Lisbon, Portugal). This article is licensed under a Creative Commons Attribution 4.0 International License (CC BY).

\section{Introduction}

\subsection{Virtual Spaces and the Business of eSport}

eSport originated in Stanford University's Artificial Intelligence Laboratory in 1972 as students gathered to play Spacewar (Li, 2016). eSport has now become a thriving industry, with revenues reaching \$1.1 billion in 2019 (Pannekeet, 2019), and international contests attended and viewed by millions globally. The primary user groups engaging and captivated by eSport, both as participants and spectators, tend to be adolescents and young people (Hamari \& Sjöblom, 2017). 'eSport' is used as an overarching term encompassing numerous eSport genres and is often referred to by synonyms such as gaming, electronic sports, virtual sports, and cyber sports (Jenny, Manning, Keiper, \& Olrich, 2016). eSport takes many forms including first person shooter games (i.e., Counter-Strike), fighting games (i.e., StreetFighter IV), multiplayer online battle arena games (i.e., League of Legends), real- 
time strategy games (i.e., StarCraftII), and sport-based video games (i.e., FIFA), all of which are owned and managed by the game developers and publishers (Funk, Pizzo, \& Baker, 2018). eSport's (largely digital) potential for inclusion (dos Santos, Moreira, Coutinho, \& Maia, 2018) lies in its virtual accessibility through online streaming platforms, like Twitch, which have been instrumental in the development, engagement, and global reach of esport.

When examining virtual spaces, it is critical to consider the, often concealed, gender dynamics to understand what influence they may have on access, engagement, and participation. Within Information and Communication Technologies (ICTs; e.g., e-commerce, computer games, emails, and the Internet), there is a known global digital gender divide, with women having lower engagement with ICTs compared to their male counterparts (Huyer \& Sikoska, 2003; Wagg, Cooke, \& Simeonova, 2019). Gender specific social and structural barriers, such as education and cultural practices, influence access and have led to this disparity. Importantly for the scope of this article, this divide has resulted in specific gendered behaviours and practices affecting virtual spaces. Accordingly, it is via empirical analysis that we explore this gendered discourse within digital gaming environments.

Hypermasculinity embedded in sporting contexts is not a new narrative. Coavoux (2019) notes the hegemonic nature of playing video games forms part of the gendered culture of adolescence reinforcing masculine domination. The opportunities for males are more prevalent as "for boys, games fit into normal forms of sociability" (Coavoux, 2019, p. 3). This has resulted in gendered differences in gaming patterns (Amazan-Hall et al., 2018; Crawford, 2005; Vossen, 2018). Therefore, research suggests that women continue to face stigmatisation, discrimination, and entry barriers into new virtual sporting paradigms and gaming networks. Despite scholars observing the rise and, in some cases equal numbers of females within gaming environments, the disparity of experience and treatment reveals contested inclusion outcomes (Paaßen, Morgenroth, \& Stratemeyer, 2017; Royse, Lee, Undrahbuyan, Hopson, \& Consalvo, 2007). Consequently, the 'male gamer stereotype' and 'cultural inaccessibility' of eSport has led to discrimination and toxic practices towards females (Crawford, 2005; Mortensen, 2018; Paaßen et al., 2017; Vossen, 2018). This emergence of toxicity and gendered practices concealed within esport frames the context of this article.

\subsection{Toxicity in Virtual Spaces}

Online communities and platforms serve many opportunities to exercise prosocial attitudes and behaviours. Märtens, Shen, Losup, and Kuipers $(2015$, p. 2) claim that "communication channels might be abused to harass and verbally assault other players" and define toxicity as the use of profane language by one player to insult or humiliate a different player. Further research suggests that online gaming toxicity and hostility against marginal groups does not discriminate and is evident across gaming platforms. Kishonna Gray's (2014) ethnography of the Xbox Live gaming community, for example, describes sustained cultures of gendered and racially motivated harassment directed at women of colour who opt to communicate with teammates via voice chat. According to the Scholars Strategy Network, "problems are worsened by gaming community leaders who claim that genderbased harassment is a 'non-issue' and dismiss their responsibility for fostering rape cultures," and warns that "unless hostile online behaviours are reduced, vulnerable people, marginalised groups, and the public generally will all be further harmed" (Miller, 2019).

This article empirically exposes the challenges associated with gendered norms and practices present within esport, whilst exploring the utility and potential for eSport to support Sport for Development (SfD) agendas. SfD refers to the intentional use of sport as a mechanism to achieve non-sport development goals. Actors and stakeholders in sport, academia, the private sector, non-profit and non-governmental organisations, government agencies and international organisations, among others, look to use sport's potential as a tool to serve personal, community, national, and international development objectives (Sportanddev.org, 2019). A critical component of the SfD movement centres on utilising sport to achieve the 2017 Sustainable Development Goals (SDGs), which outline the 17 priority areas such as peace and security, reducing inequalities, health, and education (United Nations, 2019). Such goals provide leveraging opportunities and the legitimisation of sport beyond its traditional spaces. Here, the esport industry has been recognised as a potentially innovative addition to the catalogue of mainstream sport offerings within SfD programming (Heere, 2018; Oillaux, 2018). However, underneath the veil of technology, little is understood about the quality of experience, that often young, participants encounter, especially women and girls. It is this confrontation of inclusion versus quality of experience that frames the methodological approach and theoretical frameworks applied in this article.

\subsection{Selling eSport to Outsiders?}

Due to the various forms esport can take, alongside the multiple platforms and playing contexts, constructing a universally accepted definition is complex. Moreover, there is limited consensus on how to define and classify eSport (Wagner, 2006). The most comprehensive definition was provided by Wagner (2006, p. 2) who defines eSport as "an area of sport activities in which people develop and train mental or physical abilities in the use of information and communication technologies." Yet, this presents a significant challenge as before eSport can be utilised or considered in new spaces (such as SfD) it needs to be further understood and acknowledged. 
The potential of eSport to contribute to the SfD movement and specific SDGs is slowly being realised. In December 2018, at the seventh Olympic Summit held in Lausanne, Switzerland, the International Olympic Committee (IOC) led discussions about the rapid development of eSports and the current involvement of various Olympic stakeholders. The Summit agreed that "the Olympic Movement should not ignore its growth, particularly because of its popularity among young generations around the world" (IOC, 2018). The recognition by the IOC of eSport as a rapidly growing industry has two consequences. Firstly, it gives credibility to a sport that is building mainstream capital, and secondly provides potential new opportunities for both the Olympic Movement and SfD.

eSport is still evolving as an industry and, for many external stakeholders within mainstream sport, academia and the SfD sector for example, there is a lack of knowledge and acceptance (dos Santos et al., 2018; IOC, 2018). Concerns have specifically been noted regarding the commercially driven nature of the industry compared to traditional sports' orientation as value-driven (IOC, 2018). The coming together of sport (in this case eSport) and the corporate business sector can be a beneficial, yet challenging, partnership. As we explore, this has consequences for participants when considering how eSport has exponentially grown (in both business capital and participation) in the absence of universal governance structures, and consequences for behaviours that may cause harm. This lack of regulation may hamper eSports acceptance as a credible social inclusion platform as the potential for eSport to be envisioned as an unbounded 'sport for all' tool may be questioned. Evidence suggests that digital and social inclusion, as well as gender inclusivity, are currently fragile within the eSport space.

\subsection{Social Inclusion}

Warschauer (2004) claims the concept of social inclusion well reflects imperatives of the current information era in which issues of identity, language, social participation, community, and civil society are performed and negotiated. The multiple conceptual framings and historical considerations of 'inclusion' goes beyond the scope of this article. However, in developing the empirical framework of this research, the following influences and definitions shaped the nuanced connections made between social inclusion and the eSport industry. In political and educational spheres inclusion is about the participation of all children and people and the removal of exclusionary practice (Armstrong, 2003). Participation lends itself as the key component to the inclusion paradigm. Yet, access and alienation are also the key principles of social 'exclusion' (Collins, 2003). Quality of experience and of inclusion outcomes must therefore position a host of social justice, equality, ethno-linguistic, gender, and socio-economic factors (Gidley, Hampson, Wheeler, \& Bereded-Samuel, 2010). It is the aforementioned recog- nition of 'quality' as an indicator for inclusion that drives this article's empirical analysis.

From the perspective of sport organisations, governance, and participation, social inclusion is about fairness, and changing the structure of sport to ensure that it becomes equally accessible to all members of society (Sport England, 2001). This article recognises this importance of access and participation, though centres the analysis and critique of social inclusion outcomes related to gender inclusivity within eSport by using Bailey's (2005) framework to map the quality of experience. 'Quality' here is important and will be empirically analysed through the lens of social connectivity or, as Bailey (2005) refers, spatial distances, as well as feelings of acceptance and belonging, equal opportunities, and empowerment. The tension, often seen in sport and SfD, is the misnomer between equal access and inclusion. Therefore, Bailey (2005) and Lefebvre's (1991a) theoretical accounts allow the empirical findings to investigate the quality of inclusion in relation to gender.

Gender inclusivity and equality is a foundational development objective embedded in global social inclusion agendas. Indeed, this is core to the SDGs focus on empowering all women and girls and eliminating gender-based discrimination (United Nations, 2019). Throughout this article we focus our attention on 'gender inclusivity.' Specifically, examination of gender dynamics within eSport spaces and related gendered experiences of equal participation, opportunities, and treatment. Often, especially in the context of SfD, inclusion narratives are supported by the goal of empowerment. Again, this indicates that access and participation is not a true reflection of development, unless a social outcome is accompanied by the act of engagement. This illustrates the importance of examining the 'quality' of experience as a unit of analysis to investigate gender inclusion and, more specifically, the experience of girls and women. The notion of social inclusion highlights that the rights of all should be equally invested in and promoted, and it is the action (or quality of experience) of gendered inclusion dynamics that are contested within this article.

Applying Bailey's (2005) conceptual model of social inclusion and Lefebvre's (1991a) conceptualisation of space as a theoretical grounding, we suggest that social inclusion in relation to gender is fractious and contentious within esport, in part due to the multiple and competing agendas of the industry.

\section{Theoretical Framework}

Bailey's (2005) conceptual model of social inclusion can be understood and applied through a group of social, emotional, economic, and cultural characteristics that contribute to the process of cultivating and experiencing social inclusion. Drawing upon the work of Donnelly (1996), Freiler (2001) and Bailey (2005, p. 76), we apply the connected dimensions of social inclusion: 
1) Spatial: Social inclusion relates to the proximity and the closing of social and economic distances;

2) Relational: Social inclusion is defined in terms of a sense of belonging and acceptance;

3) Functional: Social inclusion relates to the enhancement of knowledge, skills and understanding;

4) Power: Social inclusion assumes a change in the locus of control.

The fundamental principles of SfD align with Bailey's (2005) social inclusion framework, which broadly aims to: bring people together from diverse economic and social backgrounds through a shared activity or interest which is intrinsically valuable (spatial); create or incite a sense of belonging and acceptance of others, irrespective of differences (relational); offer opportunities for the enhancement and development of skills, knowledge, and competencies (functional); and increase social networks, civic pride, and community cohesion to enhance community capital (power). These four components construct quality indicators or sites of inclusion that require exploration to question gendered dynamics of esport participation.

In applying Bailey's (2005) framework of social inclusion, we also consider a deeper exploration of the inter-sectoral relationship between the commercial business entities and objectives of the eSport industry and how this impacts the quality of inclusivity in relation to gender. In doing so, we apply a philosophical analysis of space, based on the work of Henri Lefebvre and colleagues (Lefebvre, 1991a, 1991b, 2003; Lefebvre \& Réguiler, 1986/2004; Sheilds, 1999), as a frame through which the complex foundations and characteristics of this unique and largely under researched space may be deconstructed. Lefebvre's work surpasses conventional conceptualisations of space. First and foremost, space can be understood in philosophical terms (Lefebvre, 1991a; Lefebvre \& Réguiler, 1986/2004) and, in this context, takes the form of ideas, opinions, discourses, and imagination. Such spatial analysis requires the establishment of social concepts (i.e., interaction, identity), metaphysical constructs (i.e., beliefs, values), alongside understanding power relations and spatial (re)production. It is these social concepts that connect the conceptualisation of space with Bailey's (2005) inclusion framework and significantly advance previous applications by confronting and acknowledging spatial and relational dynamics with social inclusion indicators. Often seen as stagnant or passive, the conditions that both connect and disrupt the quality of experience are challenged through the intersection of Lefebvre's (1991a) triad of spatial terms and Bailey's (2005) social inclusion indicators. Lefebvre's (1991a) three spatial conceptualisations are:

1) The First Space: Thought is seen as an important philosophical precondition; a metaphysical starting point for understanding spatial construction. These ideological framings of a space could be evidenced (or 'felt') in the social dissemination of messages, ethics, and beliefs. In this case, the coming together of eSport participants, consumers, and key stakeholders through collective thought and interest.

2) The Second Space: With thought comes the production space; the combination of tangible institutions and structures, and their connections and relationships to individuals, communities and organisations that form around thought commonalities. eSport production involves multiple and diverse stakeholders, all of whom appear to share (to varying degrees) imperatives, and form production relations, with respect to increasing esport's popular appeal, reach, and potential.

3) Third Space: Beyond production, we take interest in esport as an action space; in which processes of thought and production affect individual and collective identity and behaviours. Action comprises of participants interacting, establishing groups to belong and enacting practices within eSport spaces.

Essentially, through Lefebvre's (1991a) thought, production, and action schema, a critical analysis of esport can be undertaken. This analysis illustrates internal, external, and inter-sectoral considerations as current structures and conditions threaten social inclusion, feed discriminatory cultures affecting women participants, and disrupt the lack of uptake by the SfD sector. To this conceptualisation, Bailey's (2005) framework provides four key quality indicators (spatial, relational, functional, and power) as means to empirically explore the gendered behaviours, attitudes, and actions which have manifested in each phase of esports' participatory evolution. It is this intersection of spatial analysis and inclusion indicators that allows for this nuanced approach to exploring gender dynamics, namely by providing a framework which examines the philosophical notion of esport spaces, its social construction, and how this influences the quality of inclusion experienced by its participants.

\section{3. eSport, Sport Management, and the SfD Sector}

In contrast to other sports, commercial business entities, and stakeholders, esport has not been widely embraced or accepted by the global SfD movement or by those contributing to SfD scholarly and policy level discourse. Importantly, however, it should be noted that SfD practitioners are starting to cautiously consider eSport as a viable sport intervention to support social development outcomes (Kids in the Game, 2019; Oillaux, 2018). In Schulenkorf, Sherry, and Rowe's (2017) extensive review of SfD research undertaken between 2000-2015, for instance, all virtual forms of sport (video games) 
were excluded. Such exclusion highlighted the lack of acceptance, implementation, and inter-sectional consideration between these two fields.

Since Schulenkorf et al.'s (2017) review advancements have been made, not only in the level of scholarship, but also in the continued development and professionalisation of eSport. Sport management has been particularly active in producing new forms of academic discourse around eSport (Cunningham et al., 2018; Funk et al., 2018; Heere, 2018), and the potential of eSport has been recognised, but not without contestation. With numerous perspectives globally, there remains a lack of consensus regarding eSport's place within the sporting movement (British eSports Association, 2017; Wagner, 2006). This has legal, policy, and litigation implications for sport business (Holden, Kaburakis, \& Rodenberg, 2017), which impacts eSport's access into traditional sporting frameworks and the SfD sector. This lack of clarity around eSport's status and position limits our understanding of how appropriate eSport might be as a tool to promote social inclusion and gender inclusivity.

\section{Method}

This exploratory research consisted of two main phases whereby three focus groups were followed by semistructured interviews (Bryman, 2012). Drawing on Scholz' (2019) work, we identified primary and secondary eSport stakeholders, including national eSport federations, trade unions, game publishers, teams and gamers, tournament organisers, and media entities. Additionally, SfD organisations and practitioners (example stakeholders outlined in Section 1.2) who plan to or were using eSport interventions as part of their programming, were invited to attend the focus groups. All stakeholders were invited to participate via email. Snowball sampling was then utilised to extend participant networks (Lewis-Beck, Bryman, \& Liao, 2004). Data collection was undertaken in 2019 (April to July) and included 81 participants (focus groups, $n=28, n=20, n=17$; interviews, $N=16$ ). Diverse stakeholder representation was achieved (see Tables 1 and 2) and, critically, female participation was reflective of industry trends (Taylor, 2020; Women in Games, 2018).

The methodological approach to data collection required utilising multiple tools to extract the level of information needed to apply Lefebvre's (1991a) conceptualisation of space and Bailey's (2005) inclusion indicators to our analysis. Therefore, within the focus groups, participants responded to pre-determined statements focused on the notion of space, gendered behaviours, and social inclusion, which encouraged debate and dialogue (Carey \& Asbury, 2012). Other activities included the completion of persona templates where participants reflected on their experiences and any challenges faced. Alongside these organised data collection activities, expert speakers provided multiple perspectives on the industry that provoked group discussions.
Focus groups lasted between three and three and a half hours, one was hosted in the UK, with a further two hosted in the USA. These two international contexts were chosen due to the national popularity of eSport, as well as their positioning close to some of the sector's most significant stakeholders. Focus group worksheets, recordings, and researcher reflections were used to determine key thematic areas, which were subsequently used to guide the semi-structured interviews. Themes included: current industry practices; notions of belonging and community ideals; unequal participation, toxic and male dominated environments; and eSport's potential to inhibit or encourage socially inclusive practices. Interviews enriched understanding gained through the focus groups, and typically lasted between 25-60 minutes and were primarily conducted via Skype (Hanna, 2012). All data sources were subsequently transcribed verbatim and analysed. Analysis was guided by the theoretical framework drawing from the work of Bailey (2005) and Lefebvre (1991a). Open and axial coding (Bryman, 2012) was undertaken independently by the researchers to develop initial codes. Codes were then discussed and confirmed by both members of the research team to confirm agreement and validity. Pseudonyms were provided for interviewees and focus groups to ensure confidentiality and anonymity.

From a methodological standpoint, the thematic focus around inclusion exposed and focused discussions around toxicity which defined much of the data in relation to gender. This focus led to deeper analysis of gender discrimination and how this manifested within eSport spaces. The paradox between the ideological belief in eSport, and the quality of experience encountered by women, girls, and male observers to such practices, made the SfD element of the research complex and multifaceted. It was these contestations and critiques of experience by esport participants that allowed for a rich theoretical debate.

\section{Discussion}

Through Lefebvre's (1991a) and Bailey's (2005) theoretical framework, we examined the complexity of the space and the realities of gender inclusivity within eSport. The ideological belief (thought space) is that eSport has belonging and community at its core and here lies the potential for SfD. Yet, the fractured industry, fuelled by a lack of governance (production space) had resulted in unequal participation and hypermasculine, sexualised environments encased in tribal dynamics, leading these digital gaming environments (action space) to subsequently enact toxic and discriminatory behaviours towards females.

\subsection{Competing Teams? Business vs Sport}

The origins of esport are rooted in the notion of community, and all participants identified esport as a space to 
Table 1. Focus group characteristics.

\begin{tabular}{|c|c|c|c|}
\hline Focus Group & Gender & Sector & $\begin{array}{l}\text { Titles/Games Mentioned } \\
\text { (Competing \& Spectating) }\end{array}$ \\
\hline $\begin{array}{l}1 \\
\text { London } \\
(\mathrm{N}=28)\end{array}$ & $\begin{array}{l}M=75 \%(n=21) \\
F=25 \%(n=7)\end{array}$ & $\begin{array}{l}\text { 46\%-eSport Industry }(n=13) \text { : } \\
\text { - eSport Organisations (trade } \\
\text { union, private, non-profit, } \\
\text { suppliers, sponsors) = } 6 \\
\text { - eSport Leagues = } 3 \\
\text { - eSport Team Managers = } 3 \\
\text { - Media = } 1 \\
\text { 29\%-Gamers-University Students }(n=8) \text { : } \\
\text { - Amateur = } 7 \\
\text { - Semi-Professional = } 1 \\
\text { 25\%-SfD ( } n=7): \\
\text { - Charitable Foundation }=4 \\
\text { - International Charity = } 1 \\
\text { - SfD Researchers = } 2\end{array}$ & $\begin{array}{l}\text { Call of Duty } \\
\text { FIFA } \\
\text { CounterStrike: Global Offensive } \\
\text { Fortnite } \\
\text { Overwatch } \\
\text { League of Legends } \\
\text { RPGs strategy games (i.e., Final } \\
\quad \text { Fantasy Tactics) } \\
\text { Rocket League }\end{array}$ \\
\hline $\begin{array}{l}2 \\
\text { USA } \\
(N=20)\end{array}$ & $\begin{array}{l}M=75 \%(n=15) \\
F=25 \%(n=5)\end{array}$ & $\begin{array}{l}\text { 65\%-eSport Industry }(n=13) \text { : } \\
\text { - Game Publisher = } 3 \\
\text { - Live Streaming Platform = } 1 \\
\text { - eSport Organisations (trade } \\
\text { union, private, non-profit, } \\
\text { suppliers, sponsors) = } 5 \\
\text { - eSport Team Managers = } 1 \\
\text { - Collegiate eSport Director = } 3 \\
\text { 15\%-Gamers-University Students }(n=3) \text { : } \\
\text { - Amateur = } 3 \\
\text { 20\%-SfD ( }=4 \text { ): } \\
\text { - Charitable Foundation = } 2 \\
\text { - Mental Health Non-Profit = } 1 \\
\text { - Sports Association = } 1\end{array}$ & $\begin{array}{l}\text { Rocket League } \\
\text { Dota } 2 \\
\text { Super Smash Bros } \\
\text { League of Legends } \\
\text { Overwatch } \\
\text { Rainbow Six Siege } \\
\text { NBA 2K } \\
\text { Madden } \\
\text { Playerunknown's Battlegrounds } \\
\text { League of Legends } \\
\text { Fortnite } \\
\text { StarCraft } 2 \\
\text { World of Warcraft } \\
\text { Hearthstone } \\
\text { Neverwinter }\end{array}$ \\
\hline $\begin{array}{l}3 \\
\text { USA } \\
(N=17)\end{array}$ & $\begin{array}{l}M=65 \%(n=11) \\
F=35 \%(n=6)\end{array}$ & $\begin{array}{l}\text { 88\%-Gamers-University Students }(n=15) \text { : } \\
\text { - Amateur }=10 \\
\text { - Collegiate Team }=4 \\
\text { - Professional }=1 \\
\text { 12\%-SfD }(n=2): \\
\text { - Non-Profit }=1 \\
\text { - Sports Association }=1\end{array}$ & $\begin{array}{l}\text { League of Legends } \\
\text { Overwatch } \\
\text { First Person Shooter (i.e., Call of Duty) } \\
\text { Fortnite } \\
\text { Apex Legends } \\
\text { CounterStrike: Global Offensive } \\
\text { Quake Champions } \\
\text { NBA 2K }\end{array}$ \\
\hline
\end{tabular}

belong (spatial and relational), as "eSports can give people a good outlet and community" (FG 3-USA). eSport's initial conception and purpose as a safe space of thought and connectivity, founded by gamers themselves, has evolved into a commercial industry. Herein reside competing agendas and new motivations which are constantly negotiated in what Lefebvre (1991a) considered the 'production' or second space. This creates a primary tension between the competing, yet interdependent, sport and non-sport business sectors. Unlike traditional sport, eSport operates through a business model based around the priority of selling games and growing a brand. As one interviewee states, "I would say there's almost no focus on that [social impact/responsibility] because there's such a focus on making money" (Interviewee 7).

The business focus and commitment to commercial growth has been welcomed by many. Nonetheless, when considered as a safe, communal space and source of connection (spatial and power), the risks associated with growth on participants has largely been ignored. This 
Table 2. Characteristics of interview participants.

\begin{tabular}{|c|c|c|c|}
\hline Interview & Gender & Sector & $\begin{array}{l}\text { Titles/Games Mentioned } \\
\text { (Competing \& Spectating) }\end{array}$ \\
\hline$N=16$ & $\begin{array}{l}M=75 \%(n=12) \\
F=25 \%(n=4)\end{array}$ & 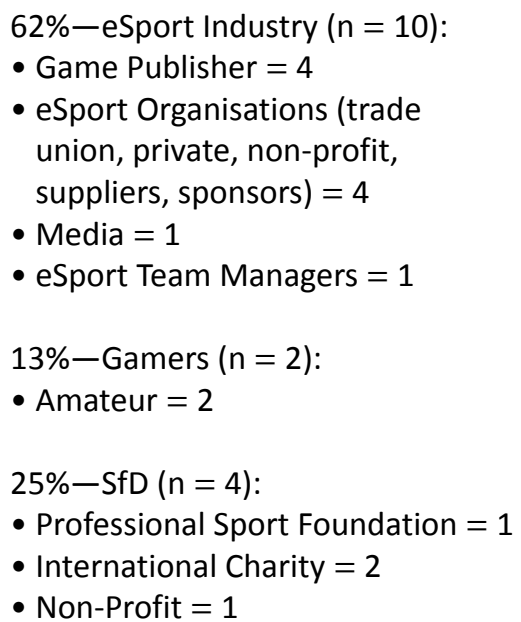 & $\begin{array}{l}\text { Madden } \\
\text { League of Legends } \\
\text { FIFA } \\
\text { Call of Duty } \\
\text { Overwatch } \\
\text { Hearthstone } \\
\text { Fortnite }\end{array}$ \\
\hline
\end{tabular}

has significant consequences for eSport's ability to be recognised as a legitimate and safe tool within SfD and, more worryingly, the detrimental effects on the often young and female participants who have been exposed to the culturally inaccessibility and toxic esport spaces (Vossen, 2018).

\subsection{Thought Space: Opportunity for Inclusion and Engagement}

The philosophical foundations of esport and its communities are founded on ideals, values, and beliefs surrounding identity and a sense of belonging. Within these predominantly online spaces, participants come together through a shared interest and passion, which "is centred on the community" (Interviewee 1). This conceptual starting point, which Bailey terms spatial construction, can be understood through the notion of collective thought. The potential for eSport to create inclusive spaces, with further links to the functional construct of social inclusion (by enhancing skills and knowledge), brings enthusiasm and interest from external stakeholders within SfD. As one participant states, eSport is a "new way to attract younger audiences, links to STEM [Science, Technology, Engineering, Maths] work...can drive female engagement" (FG 1-UK). Heere (2018, p. 4) also noted eSports' potential within SfD, as in "certain cases traditional sport might no longer serve as the most effective hook, and activities such as video gaming, dance, and music might offer equally effective returns on their investment."

This acknowledgment that esport could provide a new opportunity to engage and attract individuals has led to the identification of multiple points of entry for SfD stakeholders, as it is possible to "reach a new target group through eSports [and] Influence the gender imbal- ance" (FG 1-London). eSport has the capacity to operate in the absence of traditional gender imbalances and disparity (Kim, 2017) due to the virtual format and its intrinsic and reduced focus on the 'physical' dynamics of sport. The capability of esport to be a socially inclusive practice was noted during our research, as one participant states:

If you look at it from a very purely physical dimension, there's not I guess, those barriers which exist, which lead to separation in traditional, you know, or mainstream sports and so it's interesting to...think about why that might have happened within esport. (Interviewee 9)

Therefore, eSport has the potential to offer an inclusive environment that is open to all (regardless of gender, race, geographical location and, to some degree, disability and socio-economic status). The digital modality also heightens eSport's inclusive properties as the online format "makes it really simple, it reduces the barriers to entry. You can pick it up and play and it's just easier...a mainstream tool to spread to the masses" (Interviewee 7). Yet, the financial capacity of individuals to access competitions and purchase needed equipment may limit inclusion of certain groups (dos Santos et al., 2018).

Although esport has potential to contribute to the SfD sector as a tool to enhance social inclusion, some current practices and cultures need addressing. Power imbalances exist between participants and businesses, for example, influencing the locus of control (Bailey, 2005) with "exploitative companies. Over promising and under delivering as developers control and own the space," there are instances of "sexism being more accepted, sort of...developers like supporting that culture....The communities are much more fractured than real life" (FG 3-USA). 
The contest and interdependency between the commercial realities and priorities of the industry, juxtaposed against the values and beliefs that esport provides a safe space for online communities, resulted in a fractured reality impacting the relational quality of experience. Yet, these contested realities were not encountered by all participants.

\subsection{Production Space: Unequal Participation and Fractured Space}

The reality of eSport experiences demonstrate splintered and disrupted spaces, with competition, exclusionary boundaries, and tribal mentalities developing between eSport games and participant groups (Xue, Newman, \& Du, 2019). As one participant states: "There's very distinct separate tribes...generally split by game [and] by company too, so there's an Overwatch tribe, there's a World of Warcraft tribe..." (Interviewee 1). This serves as an exclusionary structure that antagonises the homogenous and inclusive potential of eSport by restricting, as Bailey's (2005) framework illustrates, the closing of social and economic distances between participants (spatial and relational). Tribalism, via the fractured competitive structures eSport prescribes, explicitly counters the spatial and relational dynamics many participants hold as the foundational value of their sport. This tension is also present when examining participants' awareness of gender dynamics and access to online gaming communities. As one participant claimed: "I wish there were more females involved as a girl myself" (FG 3-USA). Displays of hypermasculine behaviours and its impact were also highlighted:

Early on, you need to really think about how to make sure that girls feel safe in this world because I know the gaming industry could probably trot out a few players and say look we have a couple of women/girls that play. I mean I'm sure if I say it $90 \%$ to $10 \%$, male to female, I know it's close to that. I would assume that it doesn't feel like a very approachable thing for girls versus boys. (Interviewee 3)

Safety and a sense of acceptance (relational) is needed within the space for females to feel welcomed into digital environments. However, research has shown when women do compete, they are marginalised or rendered invisible (Paaßen et al., 2017). Even though there is a need to address the negative gendered practices, Neerukonda and Chaudhuri (2018) highlight that technology has the potential to be a mechanism to achieve gender equality. If we reflect broadly on SfD objectives, and the embedded principles to empower all women and girls (United Nations, 2019), we might question if eSport could contribute to help achieve these aims.

It must be remembered, nevertheless, a clear gap exists between technological usership, digital skills, eSport participation, and gender. Neerukonda and Chaudhuri's
(2018) examination of Artificial Intelligence, for instance, demonstrated the reproduction of human and gender biases, noting that ICTs are often designed and created within male-dominated environments (Huyer \& Sikoska, 2003). The politics of gender is also an important influence in this context due to the "global gender digital divide" where women often lack access to information and digital skills (Wagg et al., 2019, p. 1). Therefore, the resulting gender disparity in digital spaces (including esport) may be leading to the (re)production of traditional social/gender inequalities, often through the prism of male hegemony and objectification (Coy, 2009; Sherry, Osborne, \& Nicholson, 2016).

Within eSport, representations of females through avatars are often highly sexualised in nature, with female characters being eight times more likely to be wearing revealing clothing (Delamere \& Shaw, 2008; Downs, \& Smith, 2009; Vandenbosch, Driesmans, Trekels, \& Eggermont, 2017). This highly gendered space is fuelling traditional masculine stereotypes and cultures which, in part, is being addressed and tackled by businesses at the core of the industry. One interviewee from a leading game publisher states "in our values ...as a company...everything we do is very much focused on equity [and] inclusion...making everyone feel that they are equal, and that helps gender" (Interviewee 5). A further participant highlights the specific structural changes that are happening within a specific eSport title:

We're doing a lot of things internally to make sure that we are as inclusive and diverse as we claim to be...If you look at the...diversity of the Overwatch roster, we have a female engineer on there, Tracer is an LGBT woman character; she's super empowered.....There are so many role models that they've embedded...that I think people have started to identify with and resonate with, in ways that never really could have happened if they were playing...a game [that] had another huge roster of white males or women in like skimpy garments. (Interviewee 1)

This is potentially an example of how the esport space is being (re)produced by key stakeholders who are trying to address the gender imbalance and increase social inclusion by removing the hypersexual depictions of females (Delamere \& Shaw, 2008). This is an attempt to create in-game role models that may encourage more females to participate. As Paaßen et al. (2017.p. 13) claim, the "lack of visible female role models in gaming may...be an additional obstacle which keeps female gamers from visibly performing the role of a gamer." Even with examples of industry adaption to reduce the gender-related differentiation of gaming practices, when considering the fractured nature of esport, coupled with the importance of competition and beliefs surrounding who esport is 'for' (relational), there are significant negative behaviours and actions evident. 


\subsection{Action Space: Toxicity and Negative Gender Discourses}

Gender dynamics have been the focal point used to explore and contest social inclusion barriers and opportunities that are experienced and acted upon within eSport spaces. eSport has developed certain gendered norms and cultures through which women are made to feel unwelcome (Vossen, 2018). This is fuelled, in part, by the nature of eSport's competitive online environments and its participants' anonymity; essentially, the "community is still anti diversity because it can hide behind screens. Developers are [at the] centre of control and need to lead on this," as "anonymity empowers, enables, and emboldens toxic behaviour" (FG 2-USA). This has led to the proliferation of negative behaviours, displays of dominant masculine cultures, and gender inequality which has infiltrated and distorted the ideals held in the thought space.

The contested nature and outcome of the production space has led to acts of gender discrimination, which has been referred to as 'toxic gamer cultures' (Consalvo, 2012). One participant identifies "gaming has a bad reputation, especially with female audiences [and] toxic player behaviour" (FG 2-USA). By reducing acceptance and belonging (relational), as well as potential interest from females (spatial), negative gender discourses being enacted here specifically impede two of Bailey's (2005) social inclusion indicators. As "right now, it's very difficult for female gamers to enter the eSports scene," another participant noted, "...because there are so many negative stereotypes about women's competency in gaming" (FG 3-USA). Another interviewee recalls the exclusionary behaviour she was exposed to, "if you're in voice chat and you're, you know, very clearly female, people may harass you for being female in voice chat" (Interviewee 9). The culture of gender discrimination has been seen in broader video gaming through Mortensen's (2018, p. 796) research into GamerGate which identified the "protectiveness of the male space of video gaming." This defensive, hypermasculine behaviour centred around collective identity has also been seen in traditional sports, such as football, and can be likened to hooliganism (Spaaij, 2008). Notwithstanding potential, eSport in many ways suffers the same consequences as other mainstream and corporate fuelled sports enterprises despite the illusion of a new form of sporting movement and safety via virtual participation.

The toxicity and the exclusionary practices noted results in a level of concern regarding eSport's acceptance by SfD stakeholders and the mainstream sport landscape. The current behaviours paradoxically conflict with the ideological notion that eSport is a tool that can bring people together (relational). As one participant reflects:

I hate to say I think as a community right now, we are quite hypocritical....We talk about all being diverse and from different backgrounds. Together we are gamers, but then we log on and we've become a different person. (Interviewee 16)

Lefebvre's (1991a) third space (as applied to the toxicity and gender discrimination experienced within eSport gaming spaces), demonstrates the harmful consequences of inter-sectoral power negotiations that manifest when commercial entities enter esport spaces. Whilst online toxicity is not exclusive to esport, the business infrastructure in which it has been sustained, and evolved from, has done little to prevent, protect, and regulate against sexism and toxicity within competitive formats and playing cultures.

\section{Conclusion}

By using Bailey's (2005) and Lefebvre's (1991a) conceptualisation of space and social inclusion we have been able to critically analyse and explore the structures, complexities, and realities at play within the eSport industry. More importantly, we have introduced a new framework in which to consider the quality of access and participation in relation to social inclusion. The implications of this are significant for both the consideration of eSport's insertion into new spaces (SFD and mainstream sporting platforms) and the nuanced approach to scrutinising gender dynamics. This is particularly relevant to examinations of esport where the spatial, relational, and experiential outcomes are often blurred and distorted by the contestation between gaming values and brand loyalty versus the reality and quality of experience. In many ways, the intersection of Lefebvre (1991a) and Bailey (2005) allows the framing of social inclusion to go beyond access and participation and facilitates a deeper understanding and visibility of the concealment and manifestations of gender dynamics in eSport and potentially sport more broadly.

Although this research provided valuable insights into the gendered dynamics of online eSport spaces, this study was limited to two global contexts. Due to the relative scarcity of academic research (dos Santos et al., 2018), future studies should look to examine other international settings and diverse eSport communities to enhance understanding. Additionally, although this research focused on gender inclusivity, other priority areas relevant to social inclusion agendas such as disability, race, and socialeconomic status require further investigation.

More specifically, the ideological construction of the space (thought) and the potential for esport to provide a socially inclusive environment for SfD has been examined. While clear synergies and opportunities exist, there are tensions and sites of contestation present that challenge any future partnership. Participants acknowledge the fragmented and hypermasculine nature of the industry, which is exacerbated by corporate businesses agendas, that disrupt idealised notions of community (production). Fuelled by anonymity (action), this has led to toxic behaviours and gender inequalities being created within 
eSport communities. Ultimately, resulting in a contested depiction of social inclusion within the space as current practices, beliefs, and behaviours restrict esport's advancement across spatial, relational, functional, and power components (Bailey, 2005).

Despite the above critical analysis of eSport's toxic behaviours towards women, there is no lack of desire for activism from participants who recognise the need for challenging such behaviours. As one interviewee claimed, we need to "build campaigns to promote [and] stop people being so toxic....I think teams need to come together...and tackle it" (Interviewee 15). Critically, alongside gender disparity in participation, it is paramount to acknowledge the underrepresentation of women decision makers within the eSport industry as "at the top level and working in industry, very few leaders in eSports are women" (FG 2-USA). Moreover, as with any other sector (Kalaitzi, Czabanowska, Fowler-Davis, \& Brand, 2017), gender disparity is evident within eSport's organisational levels and this may affect its long-term efforts to challenge gender dynamics.

There are, however, signs of organisations and institutions advocating for diversity and inclusion enhancement (Amazan-Hall et al., 2018; AnyKey, 2019), as well as specific female participation initiatives aiming to address discrimination (GirlGamer, 2019; Women in Games, 2019). Yet, eSport is in a nascent stage of development (production phase). The current focus placed on stabilising its business models and associated legal and economic infrastructures has, significantly, halted focus towards inclusive practices, governance, and gamer welfare. We suggest this requires openness to inter-sectoral involvement to support developments around governance and regulation as the current structure appears to have limited focus on regulating eSport, with growth and consumerism outweighing the risks of marginalising participants. Critically, the ideological foundations of eSport support the SfD agenda, but in the absence of regulation, and a universal effort to enhance the quality of experience 'for all,' the blurred lines between inclusion and welfare damages eSports forecasted projection into development spaces.

\section{Acknowledgments}

This research received an internal grant from Loughborough University London's Joint Fund, and we are grateful for this funding which allowed us to conduct this research.

\section{Conflict of Interests}

The authors declare no conflict of interests.

\section{References}

Amazan-Hall, K., Chen, J. J., Chiang, K., Cullen, A. L., Deppe, M., Dormitorio, E., . . . Trammell, A. (2018).
Diversity and inclusion in eSports programs in higher education: Leading by example at $\mathrm{UCl}$. International Journal of Gaming and Computer-Mediated Simulations, 10(2), 71-80.

AnyKey. (2019). We advocate for diversity, inclusion, and equity in gaming. AnyKey Retrieved from https:// www.anykey.org/en/about

Armstrong, F. (2003). Researching the practices and processes of policy making. In F. Armstrong (Ed.), Spaced out: Policy, difference and the challenge of inclusive education (pp. 1-8). New York, NY: Kluwer Academic.

Bailey, R. (2005). Evaluating the relationship between physical education, sport and social inclusion. Educational Review, 57(1), 71-90.

British ESports Association. (2017). esports: The world of competitive gaming. Buckinghamshire: British eSports Association. Retrieved from http://www. britisheSports.org/assets/WhatiseSportsPDFOCT17 V2pdf1.pdf

Bryman, A. (2012). Social research methods (4th ed.). New York, NY: Oxford University Press.

Carey, M. A., \& Asbury, J. (2012). Focus group research. Walnut Creek, CA: Left Coast Press.

Coavoux, S. (2019). Gendered differences in video gaming. Paris: Orange Labs/Sense. Retrieved from http://www.annales.org/edit/enjeux-numeriques/ DG/2019/DG-2019-06/EnjNum19b_7Coavoux.pdf

Collins, H. (2003). Discrimination, equality and social inclusion. The Modern Law Review, 66(1), 16-43.

Consalvo, M. (2012). Confronting toxic gamer culture: A challenge for feminist game studies scholars. Ada: $A$ Journal of Gender, New Media, and Technology, 1(1), 1-6.

Coy, M. (2009). Milkshakes, lady lumps and growing up to want boobies: How the sexualisation of popular culture limits girls' horizons. Child Abuse Review: Journal of the British Association for the Study and Prevention of Child Abuse and Neglect, 18(6), 372-383.

Crawford, G. (2005). Digital gaming, sport and gender. Leisure Studies, 24(3), 259-270.

Cunningham, G. B., Fairley, S., Ferkins, L., Kerwin, S., Lock, D., Shaw, S., \& Wicker, P. (2018). eSport: Construct specifications and implications for sport management. Sport Management Review, 21(1), 1-6.

Delamere, F. M., \& Shaw, S. M. (2008). "They see it as a guy's game": The politics of gender in digital games. Leisure/Loisir, 32(2), 279-302.

Donnelly, P. (1996). Approaches to social inequality in the sociology of sport. Quest, 48, 221-242.

dos Santos, E. Z. L., Moreira, L. O., Coutinho, E. F., \& Maia, J. G. R. (2018). Assessing socioeconomic issues of the Brazilian e-sports scene. Paper presented at the XVII SBGames, Foz do Iguaçu, Brazil.

Downs, E., \& Smith, S. L. (2009). Keeping abreast of hypersexuality: A video game character content analysis. Sex Roles, 62, 721-733.

Freiler, C. (2001). From experiences of exclusion to a vision of inclusion: What needs to change. Paper pre- 
sented at CCSD/Laidlaw Foundation Conference on Social Inclusion, Ottawa, Canada.

Funk, D. C., Pizzo, A. D., \& Baker, B. J. (2018). esport management: Embracing eSport education and research opportunities. Sport Management Review, 21, 7-13.

Gidley, J. M., Hampson, G. P., Wheeler, L., \& BerededSamuel, E. (2010). From access to success: An integrated approach to quality higher education informed by social inclusion theory and practice. Higher Education Policy, 23(1), 123-147.

GirlGamer. (2019). GirlGamer eSports festival. GirlGamer. Retrieved from https://www.girlgamer.gg

Gray, K. L. (2014). Race, gender, and deviance in Xbox live: Theoretical perspectives from the virtual margins. New York, NY: Routledge.

Hamari, J., \& Sjöblom, M. (2017). What is eSports and why do people watch it? Internet Research, 27(2), 211-232.

Hanna, P. (2012). Using internet technologies (such as Skype) as a research medium: A research note. Qualitative Research, 12(2), 239-242.

Heere, B. (2018). Embracing the sportification of society: Defining e-sports through a polymorphic view on sport. Sport Management Review, 21, 21-24.

Holden, J. T., Kaburakis, A., \& Rodenberg, R. (2017). The future is now: e-Sports policy considerations and potential litigation. Journal of Legal Aspects of Sport, 27(1), 46-78.

Huyer, S., \& Sikoska, T. (2003). Overcoming the gender digital divide: Understanding ICTs and their potential for the empowerment of women (Instraw Research Paper Series 1). Santo Domingo: UN-INSTRAW.

International Olympic Committee. (2018). Communique of the 7th Olympic summit. Olympic. Retrieved from https://www.olympic.org/news/communiqueof-the-7th-olympic-summit

Jenny, S. E., Manning, R. D., Keiper, M. C., \& Olrich, T. W. (2016). Virtual(ly) athletes: Where eSports fit within the definition of "sport." Quest, 69(1), 1-18.

Kalaitzi, S., Czabanowska, K., Fowler-Davis, S., \& Brand, H. (2017). Women leadership barriers in healthcare, academia and business. Equality, Diversity and Inclusion: An International Journal, 36(5), 457-474.

Kidd, B. (2008). A new social movement: Sport for development and peace. Sport in Society, 11, 370-380.

Kids in the Game. (2019). eSports. Kids in the Game. Retrieved from https://www.kidsinthegame.com/ school-programs/king-eSports

Kim, S. J. (2017). Gender inequality in esports participation: Examining League of Legends (Unpublished Master's thesis). University of Texas, Austin, USA.

Lefebvre, H. (1991a). The production of space (D. Nicholson-Smith, Trans.). Oxford: Blackwell.

Lefebvre, H. (1991b). The critique of everyday life (Vol. 1; J. Moore, Trans.). London: Verso.

Lefebvre, H. (2003). Key writings. New York, NY: Continuum.

Lefebvre, H., \& Réguiler, C. (2004). Attempt at the rhyth- manalysis of Mediterranean cities. In Rhythmanalysis: Space, time and everyday life (pp. 85-100). London: Continuum. (Original work published 1986)

Lewis-Beck, M., Bryman, A. E., \& Liao, T. F. (2004). The Sage encyclopedia of social science research methods. Thousand Oaks, CA: Sage.

Li, R. (2016). Good luck have fun: The rise of eSports. New York, NY: Skyhorse Publishing.

Märtens, M., Shen, S., Losup, A., \& Kuipers, F. (2015). Toxicity detection in multiplayer online games. In Proceedings of the 2015 International Workshop on Network and Systems Support for Games (NetGames) (pp. 1-6). Zagreb: IEEE.

Miller, B. (2019). Countering online toxicity and hate speech. Scholars Strategy Network. Retrieved from https://scholars.org/contribution/counteringonline-toxicity-and-hate-speech

Mortensen, T. E. (2018). Anger, fear, and games: The long event of \#GamerGate. Games and Culture, 13(8), 787-806.

Neerukonda, M., \& Chaudhuri, B. (2018). Are technologies (gender)-neutral? Politics and policies of digital technologies. ASCI Journal of Management, 47, 32-44.

Oillaux, C. (2018). eSports for development? Sportanddev.org. Retrieved from https://www.sportanddev. org/en/article/news/eSports-development

Paaßen, B., Morgenroth, T., \& Stratemeyer, M. (2017). What is a true gamer? The male gamer stereotype and the marginalization of women in video game culture. Sex Roles, 76(7/8), 421-435.

Pannekeet, J. (2019). Newzoo: Global eSports economy will top \$1 billion for the first time. Newzoo. Retrieved from https://newzoo.com/insights/articles/ newzoo-global-eSports-economy-will-top-1-billionfor-the-first-time-in-2019

Royse, P., Lee, J., Undrahbuyan, B., Hopson, M., \& Consalvo, M. (2007). Women and games: Technologies of the gendered self. New Media \& Society, 9(4), 555-576.

Scholz, T. M. (2019). esports is business: Management in the world of competitive gaming. Basingstoke: Palgrave Macmillan.

Schulenkorf, N., Sherry, E., \& Rowe, K. (2017). Global sport for development. In N. Schulenkorf \& S. Frawley (Eds.), Critical issues in global sport management (pp. 176-191). Oxon: Routledge.

Sheilds, R. (1999). Lefebvre, love \& struggle: Spatial dialectics. New York, NY: Routledge.

Sherry, E., Osborne, A., \& Nicholson, M. (2016). Images of sports women: A review. Sex Roles, 74(7/8), 299-309.

Spaaij, R. (2008). Men like us, boys like them: Violence, masculinity, and collective identity in football hooliganism. Journal of Sport and Social Issues, 32(4), 369-392.

Sport England. (2001). Making English sport inclusive: Equity guidelines for governing bodies. London: Sport England. 
Sportanddev.org. (2019). What is sport and development? Sportanddev.org. Retrieved from https:// www.sportanddev.org/en/learn-more/what-sportand-development

Taylor, M. (2020). UK games industry census. UKIE. Retrieved from https://ukie.org.uk/UK-games-industrycensus-2020

Trepte, S., Reinecke, L., \& Juechems, K. (2012). The social side of gaming: How playing online computer games creates online and offline social support. Computers in Human Behavior, 28, 832-839.

United Nations. (2019). About the sustainable development goals. United Nations. Retrieved from https://www.un.org/sustainabledevelopment/ sustainable-development-goals

Vandenbosch, L., Driesmans, K., Trekels, J., \& Eggermont, S. (2017). Sexualized video game avatars and selfobjectification in adolescents: The role of gender congruency and activation frequency. Media Psychology, 20(2), 221-239.

Vossen, E. (2018). On the cultural inaccessibility of gaming: Invading, creating, and reclaiming the cultural clubhouse (Unpublished Doctoral dissertation). Uni- versity of Waterloo, Waterloo, Canada.

Wagg, S., Cooke, L., \& Simeonova, B. (2019). Digital inclusion and women's health and well-being in rural communities. In J. S. Yates \& E. R. Rice (Eds.), Oxford handbook of digital technology and society (pp. 111-135). Oxford: Oxford University Press.

Wagner, M. (2006). On the scientific relevance of eSports. In Proceedings of the 2006 International Conference on Internet Computing and Conference on Computer Game Development (pp. 437-440). Las Vegas, NV: CSREA Press.

Warschauer, M. (2004). Technology and social inclusion: Rethinking the digital divide. Cambridge, MA: MIT Press.

Women in Games. (2018). Women in eSports. Women in Games. Retrieved from http://www.womeningames. org/women-in-eSports

Women in Games. (2019). Women in games. Women in Games. Retrieved from http://www.womeningames. org/about

Xue, H., Newman, J. I., \& Du, J. (2019). Narratives, identity and community in eSports. Leisure Studies, 38(6), 845-861.

\section{About the Authors}

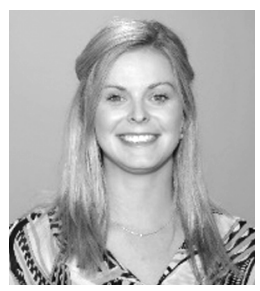

Emily Jane Hayday (PhD) is a Sport Business Lecturer at Loughborough University London. Her research specifically focuses on sport mega-events legacies and during her PhD she investigated the sport participation legacy and policy implementation processes undertaken within National Governing Bodies. Emily's additional research priority explores how esport could be used as a social development tool, by examining esport communities, its potential as a site for social inclusion, and current practices of corporate social responsibility within the eSport industry.

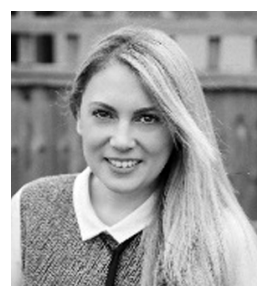

Holly Collison (PhD) is a Lecturer at Loughborough University London in the Institute for Sport Business. Holly is an Anthropologist in the field of Sport for Development and Peace (SDP) and has completed extensive fieldwork in Africa and South East Asia examining post-conflict development, social dysfunction, and violence. Her research explores youth identity, notions of community, sport for prevention interventions, sport and social disruption, and grassroots perspectives and experiences of SDP. 